\title{
Cerebral dopamine neurotrophic factor protects and repairs dopamine neurons by novel mechanism
}

\author{
Päivi Lindholm $\mathbb{D}^{1}$ and Mart Saarma $\mathbb{D}^{1 凶}$ \\ (c) The Author(s) 2021
}

\begin{abstract}
Midbrain dopamine neurons deteriorate in Parkinson's disease (PD) that is a progressive neurodegenerative movement disorder. No cure is available that would stop the dopaminergic decline or restore function of injured neurons in PD. Neurotrophic factors (NTFs), e.g., glial cell line-derived neurotrophic factor (GDNF) are small, secreted proteins that promote neuron survival during mammalian development and regulate adult neuronal plasticity, and they are studied as potential therapeutic agents for the treatment of neurodegenerative diseases. However, results from clinical trials of GDNF and related NTF neurturin (NRTN) in PD have been modest so far. In this review, we focus on cerebral dopamine neurotrophic factor (CDNF), an unconventional neurotrophic protein. CDNF delivered to the brain parenchyma protects and restores dopamine neurons in animal models of PD. In a recent Phase I-II clinical trial CDNF was found safe and well tolerated. CDNF deletion in mice led to age-dependent functional changes in the brain dopaminergic system and loss of enteric neurons resulting in slower gastrointestinal motility. These defects in Cdnf ${ }^{-1-}$ mice intriguingly resemble deficiencies observed in early stage PD. Different from classical NTFs, CDNF can function both as an extracellular trophic factor and as an intracellular, endoplasmic reticulum (ER) luminal protein that protects neurons and other cell types against ER stress. Similarly to the homologous mesencephalic astrocyte-derived neurotrophic factor (MANF), CDNF is able to regulate ER stress-induced unfolded protein response (UPR) signaling and promote protein homeostasis in the ER. Since ER stress is thought to be one of the pathophysiological mechanisms contributing to the dopaminergic degeneration in PD, CDNF, and its small-molecule derivatives that are under development may provide useful tools for experimental medicine and future therapies for the treatment of PD and other neurodegenerative protein-misfolding diseases.
\end{abstract}

Molecular Psychiatry (2022) 27:1310-1321; https://doi.org/10.1038/s41380-021-01394-6

\section{INTRODUCTION}

Increased life expectancy and a growing aging population are leading to an increase in the incidence of age-related diseases, including Parkinson's disease (PD) which affects $1 \%$ of population over 60 years of age [1], and with more than 6 million people diagnosed with PD globally [2]. PD is a progressing neurodegenerative movement disorder, in which midbrain dopamine (DA) neurons in the substantia nigra (SN) degenerate and die. Major motor symptoms of PD are slowness of movement, resting tremor, rigidity, and postural instability that appear when there is about $30 \%$ loss of DA neurons in the SN and $50-60 \%$ reduction in striatal DA axon terminals [3]. Patients with PD also suffer from non-motor symptoms, including constipation, hyposmia, depression, lack of motivation, sleep disorders, and cognitive decline that significantly decrease quality of life $[4,5]$.

Although a few toxins and genetic mutations are known to cause PD, the etiology is unknown in majority of cases. While precise mechanisms of DA neuron death are unclear, increasing body of evidence suggests that protein aggregation, mitochondrial dysfunction, inflammation, and reduced growth factor levels are involved in the molecular pathogenesis of PD $[6,7]$. Aggregation of misfolded a-synuclein (aSyn), a major component of intraneuronal Lewy bodies, may possibly cause endoplasmic reticulum (ER) stress in DA neurons leading to neuronal death
$[8,9]$. Lewy body pathology can be widespread in the central nervous system (CNS) as well as in the peripheral nervous system (PNS) including the enteric nervous system (ENS) [10]. The non-motor symptoms of PD can be related to the dysfunction of DA and other neurotransmitter systems, such as the noradrenergic and cholinergic systems [4]. However, the neuropathological mechanisms behind the non-motor symptoms are largely unknown.

Treatments are available that can improve motor symptoms of PD in most patients, but no disease-modifying therapy exists. Future therapies should include interventions that slow down or prevent the degeneration and death of DA neurons, regenerate the remaining DA neurons and increase their functional activity. They should also alleviate non-motor symptoms of PD. Neurotrophic factors (NTFs) hold great promise as drugs that could promote neuroprotection of DA neurons, and even have the capacity to regenerate them. NTFs are small, secreted proteins that promote neuronal survival, regulate development, function and maintenance of neurons, and advance neuronal recovery from injury [5, 11, 12]. Glial cell line-derived neurotrophic factor (GDNF) family ligands (GFLs) GDNF (Figs. 1C, D and 3A) and NRTN have been shown to be efficient in protecting DA neurons in rodent and non-human primate (NHP) models of PD, but have only shown modest effects in Phase II clinical trials in PD patients

${ }^{1}$ Institute of Biotechnology, Helsinki Institute of Life Science, University of Helsinki, Fl-00014 Helsinki, Finland. ${ }^{凶}$ email: mart.saarma@helsinki.fi 
A

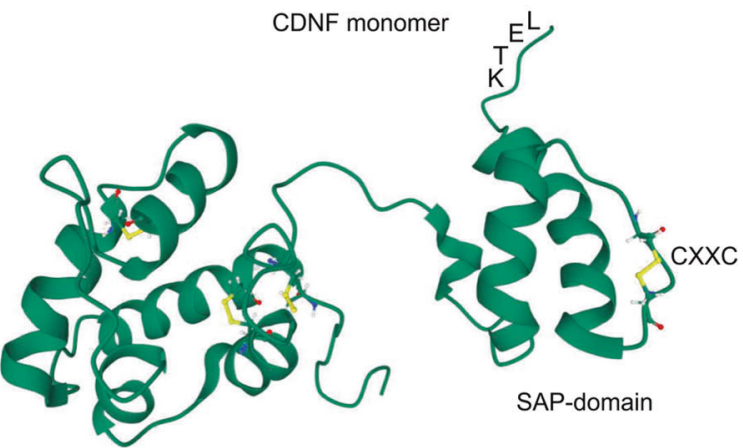

Saposin-like domain

B

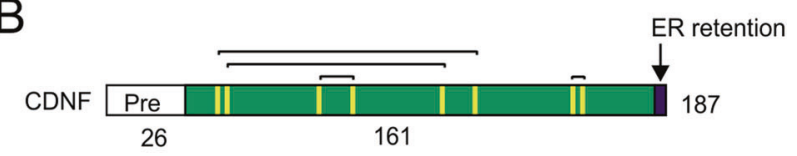

MANF

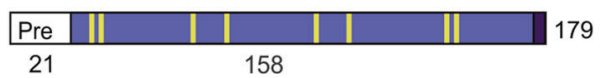

C

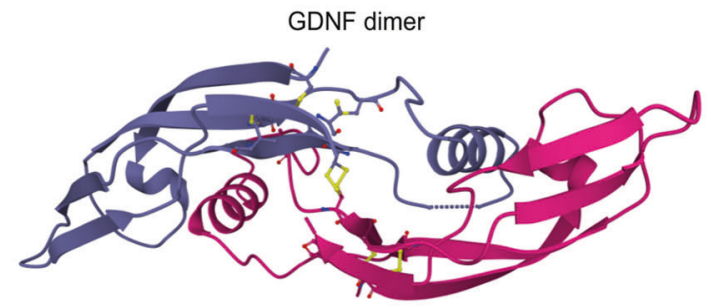

D GDNF

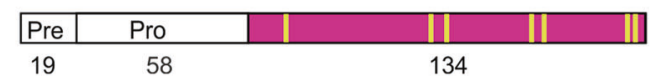

Fig. 1 Structural features of human CDNF, MANF, and GDNF proteins. A CDNF (PDB ID: 4BIT [30]) is a monomeric protein. It has an amino-terminal saposin-like domain that may mediate interaction with lipids, and a carboxy-terminal SAP (SAF-A/B, Acinus, and PIAS) domain. The CXXC motif (CRAC and CKGC in CDNF and MANF, respectively) forming a cysteine bridge is located in the C-terminal domain. Cysteine bridges stabilizing the 3D structure are shown in yellow. An ER retention signal (KTEL) is in the C-terminus of CDNF. B Primary structure of CDNF and MANF. CDNF/MANF proteins have an $\mathrm{N}$-terminal signal peptide directing them to the ER (Pre). Conserved cysteine residues in mature CDNF (green) and MANF (blue) are indicated as yellow bars, and disulfide bridges as black connecting lines. Human mature CDNF and MANF consist of 161 and 158 amino acid residues, respectively, and the amino acid identity between them is 59\%. C Two GDNF (PDB ID: 1AGQ [126]) monomers (molecular mass $15 \mathrm{kDa}$; indicated in blue and red) are connected by an intermolecular disulfide bridge (in yellow) to form a homodimer. D GDNF primary structure contains a signal sequence (Pre) directing it to the secretory pathway, a pro-sequence that is enzymatically cleaved releasing mature GDNF (red) with seven conserved cysteines (in yellow). Number of amino acid residues is indicated.

$[5,13,14]$. GDNF has not been shown to be neuroprotective in the rodent aSyn model of PD, where aSyn was overexpressed by viral vectors [15], but it in vitro and in vivo protects DA neurons from accumulation of misfolded aSyn [16]. Why have GDNF and NRTN given modest therapeutic effects in clinical trials so far? One of the reasons is that patient populations with advanced PD were treated in the Phase II clinical trials [17, 18]. Five years after clinical diagnosis, PD patients have almost no striatal dopaminergic fibers left and have pronounced loss of DA neuron cell bodies in the SN
[19]. Another important aspect is limited diffusion of GDNF and NRTN in brain parenchyma that can decrease target engagement $[5,14]$. A major limitation of NTF therapy is the requirement for their intracranial delivery using invasive brain stereotactic surgery, as NTF proteins do not cross the blood-brain barrier (BBB). In order to find out the real value of NTF therapy, several factors should be taken into consideration. Firstly, treatment should be started as soon as possible following the clinical diagnosis of PD. However, currently this is regulated by ethical considerations, which do not allow invasive surgery for the treatment of early stage PD patients. Secondly, gene technology and protein design can be used to improve the therapeutic and pharmacokinetic properties of NTFs. Thirdly, it is possible to search for new trophic factors and neurotrophic small molecules with better therapeutic properties.

We have discovered a protein with NTF properties, named cerebral dopamine neurotrophic factor (CDNF) [20], that together with the related mesencephalic astrocyte-derived neurotrophic factor (MANF, also known as ARMET) [21], form a novel evolutionarily conserved family of unconventional NTFs [22-27]. CDNF and MANF have neurotrophic properties but they otherwise dramatically differ from other known NTFs (Table 1). They have a unique structure, mode of action and they can promote cellular protein homeostasis by regulating ER stress, regulate inflammation and support neuron survival in animal models of PD [22-27]. Surprisingly, variants of CDNF can cross through the BBB thus opening a new possibility for a systemic administration of this neurotrophic drug [28]. In this review, we discuss the structure, cellular effects, biology, and therapeutic potential of CDNF. We also briefly introduce characteristic features of MANF in order to give an overview of CDNF/MANF protein family.

\section{CDNF and MANF are structurally unique proteins regulating} ER homeostasis

The three-dimensional structures of mature CDNF and MANF proteins consist of a unique combination of two domains, an amino-terminal (N-terminal) saposin-like domain and a carboxyterminal (C-terminal) SAF-A/B, Acinus, and PIAS (SAP) domain [2931] (Fig. 1A). The domains are connected by a flexible linker region suggesting that they can perform separate functions [29-31]. Since saposin-like proteins usually interact with lipids or membranes, it is probable that the N-terminal domain mediates the CDNF/MANF interaction with lipids [31]. Indeed, MANF was shown to directly bind sulfoglycolipid 3-O-sulfogalactosylceramide (sulfatide) possibly via its $\mathrm{N}$-terminal domain [32]. The C-terminal SAPdomain is important for the neuroprotective activity of MANF, since it can independently promote the survival of neurons in vitro [29]. In their primary structure, CDNF/MANF proteins have eight cysteine residues with conserved spacing, which are important for the protein fold (Fig. 1B). Three intramolecular disulfide bonds stabilize the saposin fold of the N-terminal domain and a fourth disulfide bond can be formed in a CXXC motif in the SAPdomain [31]. When the CXXC motif was mutated, neuroprotective activity of MANF was lost indicating that this motif is crucial for the biological activity of MANF [33]. At the very C-terminal end, CDNF and MANF have an ER retrieval sequence resembling the canonical lysine-aspartic acid-glutamic acid-leucine (KDEL) sequence preventing protein secretion from the $\operatorname{ER}[34,35]$ (Figs. $1 A, B$ and $3 C$ ). In support for the role of KDEL-receptors (KDEL-Rs) in regulating CDNF and MANF secretion, deletion of the $\mathrm{C}$-terminal $\mathrm{KDEL}$-like sequence increases their release from cells [33-37]. Human CDNF has potential sites for $\mathrm{N}$-linked and O-linked glycosylation but glycosylation is not required for its secretion $[20,38]$.

In cells, CDNF and MANF reside mainly in the lumen of the ER $[39,40]$ where, especially MANF and likely CDNF have an important role in regulating of ER protein homeostasis and promoting cell survival under ER stress $[23,26]$. ER stress is a 
Table 1. General properties of CDNF, GDNF, and NRTN proteins.

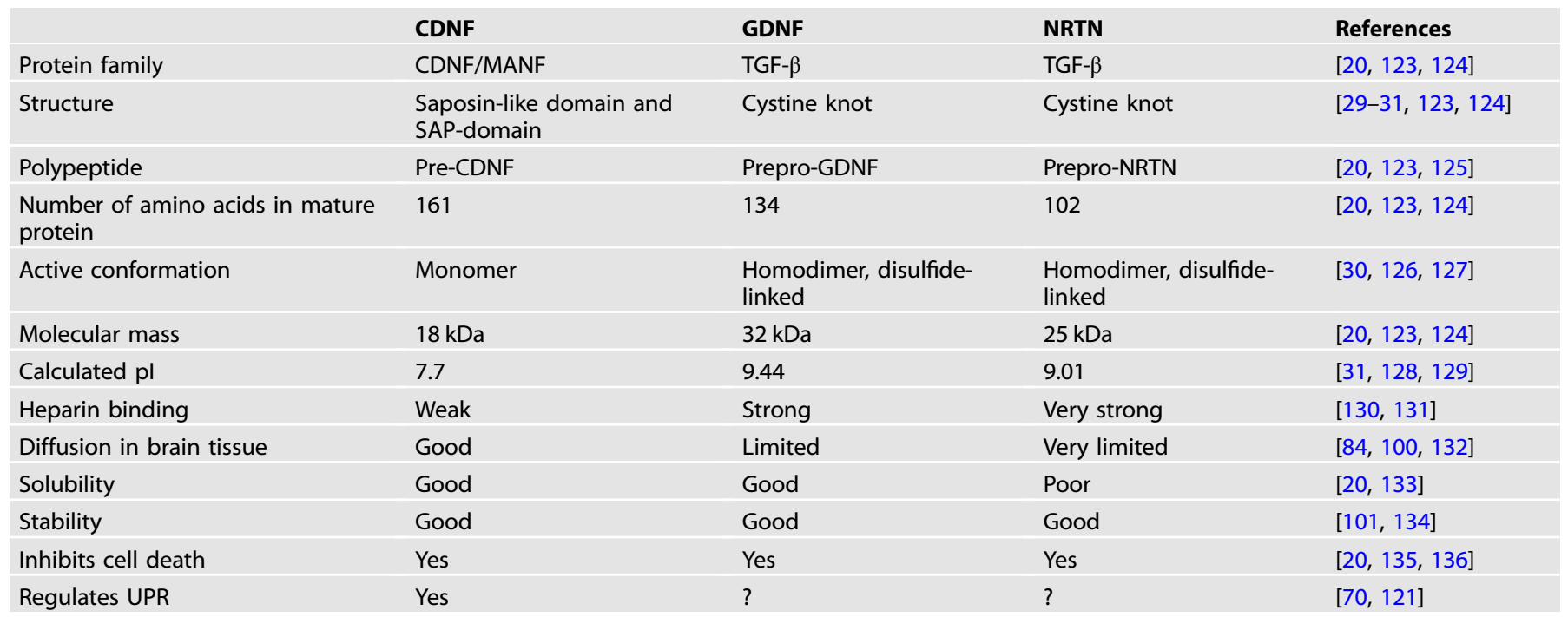

condition where protein-folding capacity of the ER is overwhelmed resulting in accumulation of unfolded proteins in the lumen. It can be due to various physiological and pathological conditions, including increased demand of protein secretion, synthesis of mutant proteins, hypoxia, nutrient deprivation, or depletion of ER calcium. To overcome ER stress, an adaptive signal transduction pathway termed the unfolded protein response (UPR) is activated to restore ER protein homeostasis by increasing expression of chaperones to improve protein folding capacity, to attenuate translation to reduce protein folding load, and to enhance ER-associated protein degradation (ERAD) to remove misfolded proteins [41]. Three ER transmembrane proteins inositol-requiring enzyme 1a (IRE1a; also known as ERN1), protein kinase R-like ER kinase (PERK; also known as EIF2AK3) and activating transcription factor 6 (ATF6) function as sensors for disturbances in ER protein homeostasis in mammalian cells, and their activation induces UPR signaling [41-44] (Fig. 2A). If recovery of ER homeostasis fails, UPR can become chronic leading to apoptosis [45]. UPR has been associated with pathophysiology of several neurodegenerative protein-misfolding diseases, including PD [46-48].

Based on the structural homology between CDNF and MANF, we can hypothesize that their molecular mechanism of cytoprotective action has some similar features. Both CDNF and MANF are widely expressed in mammalian tissues although with differential levels $[20,49,50]$ suggesting tissue-specific functions. The MANF promoter contains ER stress response elements recognized by UPR-induced transcription factors $[39,51,52]$ and its expression is increased in ER stress-related conditions [39, 53-55]. Biological importance of endogenous MANF for the maintenance of ER protein homeostasis was demonstrated in conventional and pancreas-specific MANF knockout mice, where chronic UPR activation contributes to the loss of pancreatic insulin producing beta cell mass and development of diabetes mellitus-like condition $[56,57]$. In cultured cells, silencing of MANF led to activation of UPR and increased susceptibility to ER stress-induced cell death [58]. UPR activation was also detected in Caenorhabditis elegans $[59,60]$ and Drosophila melanogaster [61] due to the loss of functional MANF. MANF interacts with an ER chaperone BiP $[62,63]$, and was shown to prolong BiP interaction with its clients thus promoting protein-folding homeostasis in the ER [64]. We recently observed that intracellular MANF is able to promote the survival of cultured neurons by a mechanism relying on the activity of either IRE1a or PERK pathways [63]. However, MANF interaction with $\mathrm{BiP}$ was not required for its neuroprotective activity [63]. Further studies demonstrated that MANF directly binds to the luminal domain of IRE1a [65]. MANF binding decreased ER stress-induced oligomerization and phosphorylation of IRE1a, leading to attenuation of UPR [65]. Under homeostatic conditions, BiP binds to the luminal domain of IRE1a, PERK, and ATF6 keeping them inactive, whereas in ER stress BiP is dissociated triggering the activation of UPR sensors [41]. MANF was shown to compete with BiP for the interaction with IRE1a suggesting that MANF is able to bind and regulate IRE1a activity only when BiP is dissociated, as is the case in ER stress [65]. Thus, IRE1 a could act as MANF receptor in the ER and MANF, by moderating IRE1 a activity could promote cell survival during ER stress [65] (Fig. 2B). The biological function of MANF in regulating ER protein homeostasis was further supported by protein-protein interaction studies suggesting that MANF is a member of a large multiprotein complex of ER chaperones [63]. A recent report demonstrated that MANF can function as a chaperone in the ER, although it does not show structural or sequence homologies to known chaperone families [66].

In ER stress-related disease models in vivo, expression of endogenous CDNF was reported to increase after cerebral or myocardial ischemia $[67,68]$. In vitro, ER stress-inducing tunicamycin treatment increased CDNF expression in cardiomyocytes [69] but not in an osteosarcoma-derived cell line [58]. Thus, responsiveness of CDNF to ER stress may depend on cell type. However, intracellular CDNF was cytoprotective against ER stress and able to regulate UPR. Overexpression of CDNF alleviated ER stress-induced astrocyte damage, and attenuated the expression of ER stress-induced apoptotic proteins in neurons [70,71]. What is more, CDNF overexpression may induce a mild adaptive conditioning UPR that prepares cells to encounter ER stress and protects cells in this way [70]. Whether CDNF can regulate UPR via binding to UPR sensors, similarly to the interaction of MANF and IRE1a, is unknown (Fig. 2B).

Although CDNF and MANF are largely retained in cells, their secretion is increased in ER stress when ER calcium is depleted $[36,62,67]$. Secreted CDNF and MANF may function as autocrine or paracrine trophic factors, promoting cell survival. In accordance with their potential trophic activities, endogenous CDNF and MANF can be detected in human serum [72, 73]. Circulating concentrations of CDNF were not altered in PD patients while MANF concentrations were significantly increased and positively correlated with the Beck Depression Inventory scoring, which is 

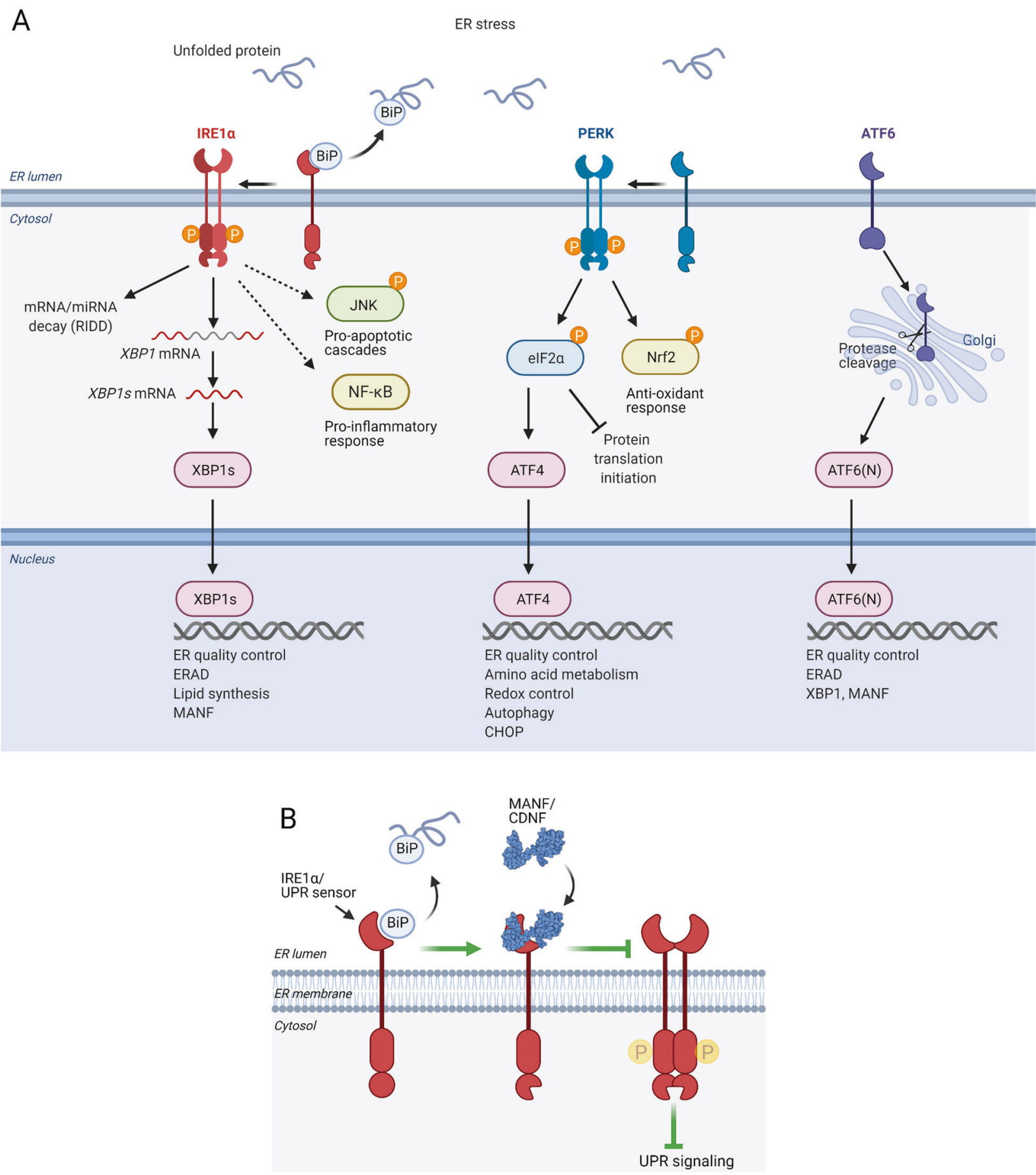

used to measure the severity of depression. This suggests that further studies would be useful to test whether blood MANF levels can be used as a clinical marker of PD [73]. It has been proposed that serum MANF functions as a systemic regulator of inflammation and metabolic homeostasis, thus protecting against agerelated deterioration [74].

\section{Extracellular trophic activities and plasma membrane receptors}

Evidently CDNF and MANF can protect neurons as extracellular trophic factors, as demonstrated for example in animal models of PD (as discussed later in detail), and as potential intracellular regulators of protein homeostasis in the ER. Whether these two seemingly different cytoprotective activities of CDNF and MANF engage the same or different intracellular signaling pathways and molecular mechanisms is under investigation.

In contrast to classical NTFs, publications demonstrating survival-promoting effects of extracellular CDNF and MANF on naive neurons are limited. Exogenous CDNF was able to support the development and survival of enteric DA neurons originating from enteric neural crest-derived cells in vitro [75], whereas it did not support the survival of cultured postnatal midbrain DA neurons [76]. CDNF promoted neither the survival of superior cervical ganglion (SCG) neurons, motoneurons, nor dorsal root ganglion neurons in contrast to nerve growth factor (NGF) [20]. MANF protein added to the cell culture was unable to promote 
Fig. 2 General cellular scheme of unfolded protein response (UPR), and a potential mechanism how MANF and CDNF are regulating UPR in the ER. A UPR is activated by ATF6, PERK, and IRE1 $\alpha$ sensors located in the ER membrane of mammalian cells. In nonstressed conditions, ER chaperone BiP associates to the luminal domain of IRE1 $\alpha$, PERK, and ATF6 keeping them inactive. When unfolded proteins accumulate in the ER lumen causing ER stress, BiP is dissociated from the sensors, favoring activation of UPR. Unfolded proteins may also directly bind and activate IRE $1 \alpha$ and PERK [137-139]. Upon activation, IRE1 $\alpha$ forms homodimers and oligomers leading activation of its cytosolic kinase domain, trans-autophoshorylation and stimulation of its ribonuclease (RNase) activity. The active RNase domain of IRE1 $\alpha$ removes an intron from XBP1 mRNA leading to the expression of transcription factor XBP1s, which induces transcription of genes related to ER quality control, ERassociated degradation (ERAD), and lipid synthesis. The RNase of IRE1 $\alpha$ may also degrade ER-targeted mRNAs and miRNAs through regulated IRE1-dependent decay (RIDD), thus decreasing protein folding demand. IRE1 $\alpha$ can-via adapter TRAF2-regulate c-Jun N-terminal kinase (JNK) activation and apoptosis pathways, and NF- $\mathrm{KB}$ activation and pro-inflammatory signaling. Activated PERK phosphorylates $\alpha$-subunit of eukaryotic initiation factor 2 (elF2), leading to transient arrest of translation initiation and decreased general protein synthesis. PERK also phosphorylates transcription factor nuclear factor, erythroid 2-related factor 2 (NRF2) that regulates antioxidant response genes [140, 141]. Translation of ATF4 transcription factor is favored in conditions of limited elF2 $\alpha$. ATF4 induces transcription of genes involved in protein folding, redox control, amino acid metabolism and autophagy. Under prolonged ER stress, ATF4 induces pro-apoptotic transcription factor CCAAT/enhancer-binding protein homologous protein (CHOP). Upon activation, ATF6 translocates to the Golgi where it is cleaved by endopeptidases, releasing ATF6(N) fragment that functions as a transcription factor. ATF6(N) induces expression of XBP1 mRNA and components of ERAD. XBP1s and ATF6(N) can induce MANF expression. For in-depth discussion of UPR please see excellent reviews [142-144]. B MANF directly interacts with the ER luminal domain of UPR sensor IRE1 $\alpha$. MANF binding decreases ER stress-induced oligomerization and phosphorylation of IRE1 $\alpha$, leading to attenuation of UPR. BiP prevents MANF interaction with IRE1 $\alpha$, while MANF at physiological concentrations does not affect BiP-IRE1 $\alpha$ interaction, which suggests that MANF binds and regulates the sensor activity after dissociation of BiP [65]. Similarly to MANF, CDNF may interact with a UPR sensor to regulate UPR.

the survival of naive DA or SCG neurons, in contrast to GDNF and NGF $[29,63]$. Compared to naive neurons, the survival-promoting effects of CDNF and MANF have been more prominent on injured or stressed neurons $[20,29,63]$. For example, exogenous CDNF protected DA neurons against toxicity of aSyn oligomers [30]. CDNF also protected hippocampal cells against synaptotoxicity of amyloid- $\beta$ peptide oligomers likely through regulation of ER stress [77]. In addition to neurons, MANF has various effects on nonneuronal cells. Exogenous MANF stimulated the proliferation of mouse and human pancreatic beta cells $[56,57,78]$ that, compared many other cell types, have high physiological ER stress due to synthesis and secretion of insulin [79]. MANF also protected cultured embryonic DA neurons against ER stress and decreased induction of UPR genes via a mechanism dependent on either IRE1 or PERK pathways [63] suggesting that exogenous MANF, similarly to intracellular MANF, can promote neuron survival through regulating UPR. How could exogenous MANF regulate UPR signaling in the ER? Bai and colleagues provided one possible answer to this by proposing that extracellular MANF bound to sulfatide can be endocytosed to cells where it mediates cytoprotection by promoting ER homeostasis [32] (Fig. 3B). The molecular mechanism of the potential endocytosis of MANFsulfatide and subsequent molecular events remain to be resolved.

Protein receptors proposed to interact with CDNF and MANF on the PM are KDEL-R and neuroplastin (NPTN) $[36,67,80]$ (Fig. 3B). KDEL-R is mainly localized in the Golgi but it was also detected in the PM where it could bind CDNF and MANF through C-terminal KDEL-like sequences [36, 67] (Fig. 3B). Protective effects of exogenous CDNF against myocardial ischemia/reperfusion injury was dependent on the presence of the C-terminal lysinethreonine-glutamic acid-leucine (KTEL) sequence and PI3K-Akt signaling pathway [67]. However, the C-terminal argininethreonine-aspartic acid-leucine (RTDL) sequence of MANF was dispensable for its neuroprotective activity in a model of cerebral ischemia [33], suggesting alternative mechanisms for exogenous MANF activity. Recently, NPTN was identified as a novel PM receptor for MANF [80] (Fig. 3B). Direct binding of MANF to NPTN decreased ER stress-mediated inflammation and cell death [80]. However, it is unclear whether NTPN is the major PM receptor for MANF. Different from MANF, CDNF does not bind NPTN or sulfatide $[32,80]$, suggesting that cell surface receptors for CDNF remain to be discovered.

\section{CDNF and MANF knockout neuronal phenotypes}

There are only few studies reporting endogenous levels of CDNF in patients with PD, obviously due to limited availability of tissue material. In hippocampal samples of PD patients, CDNF levels were increased while GDNF levels were decreased suggesting that these factors could represent potential targets for modification to help attenuate cognitive decline in PD [81].

Biological functions of CDNF in the nervous system has been studied using mouse and zebrafish knockout models [75, 82, 83]. These studies indicate that CDNF expression is important for the development and maintenance of various neuronal types and circuits rather than specifically for DA neurons. Although CDNF protects midbrain DA neurons in rodent models of PD [20,84-89], no gross anatomical changes were observed in the midbrain DA system of conventional $\mathrm{Cdnf}^{-1-}$ mice [83]. Numbers of DA neurons in the SNpc, density of tyrosine hydroxylase (TH)- or dopamine transporter (DAT)-positive fibers in the striatum, or striatal DA or DA metabolite levels did not differ between $C d n f^{-1-}$ and $C d n f^{+/+}$mice [83]. However, Cdnf deletion did lead to changes of dopaminergic neurotransmission, as amphetamine administration induced an increased hyperlocomotor response, possibly resulting from altered function of DAT in the dopaminergic axon terminals in striatum of $\mathrm{Cdnf}^{-1-}$ mice [83]. Expression of UPR genes was not altered in the SN or striatum of $\mathrm{Cdnf}^{-1-}$ mice, suggesting that CDNF expression is not essential for the maintenance of ER protein homeostasis in the midbrain DA system [83]. Further characterization of $\mathrm{Cdnf}^{-1-}$ mice demonstrated the importance of Cdnf expression for the development and maintenance of neurons in the ENS. Cdnf ${ }^{-1-}$ mice suffered from an age-dependent loss of enteric neurons due to increased neurodegeneration and autophagy observed selectively in the submucosal plexus of the intestinal wall, leading to slowed gastrointestinal motility [83]. Cdnf expression was found to be necessary for the normal development and survival of enteric DA neurons since Cdnf deletion resulted in loss of DA neuronal markers in the submucosal plexus [75]. The observed ENS defect in $C d n f^{-1-}$ mice was not only for DA neurons as the numbers of NOS-, GABA-, and CGRP-expressing neurons were also decreased [75]. The data suggest that the observed functional changes in the brain dopaminergic system and loss of ENS neurons in $C d n f^{-1-}$ mice resemble deficiencies observed in early stage PD [83]. In a human population study, mutations in CDNF gene were not identified in patients with early-stage PD [90]. However, a trend towards susceptibility to PD was observed in subjects carrying an allele of an intronic CDNF single nucleotide polymorphism (SNP) [90].

Zebrafish cdnf mutants generated using CRISPR/Cas9-genome editing were viable, fertile, and had no gross morphologic phenotype [82]. Importantly, loss of cdnf caused impairments 

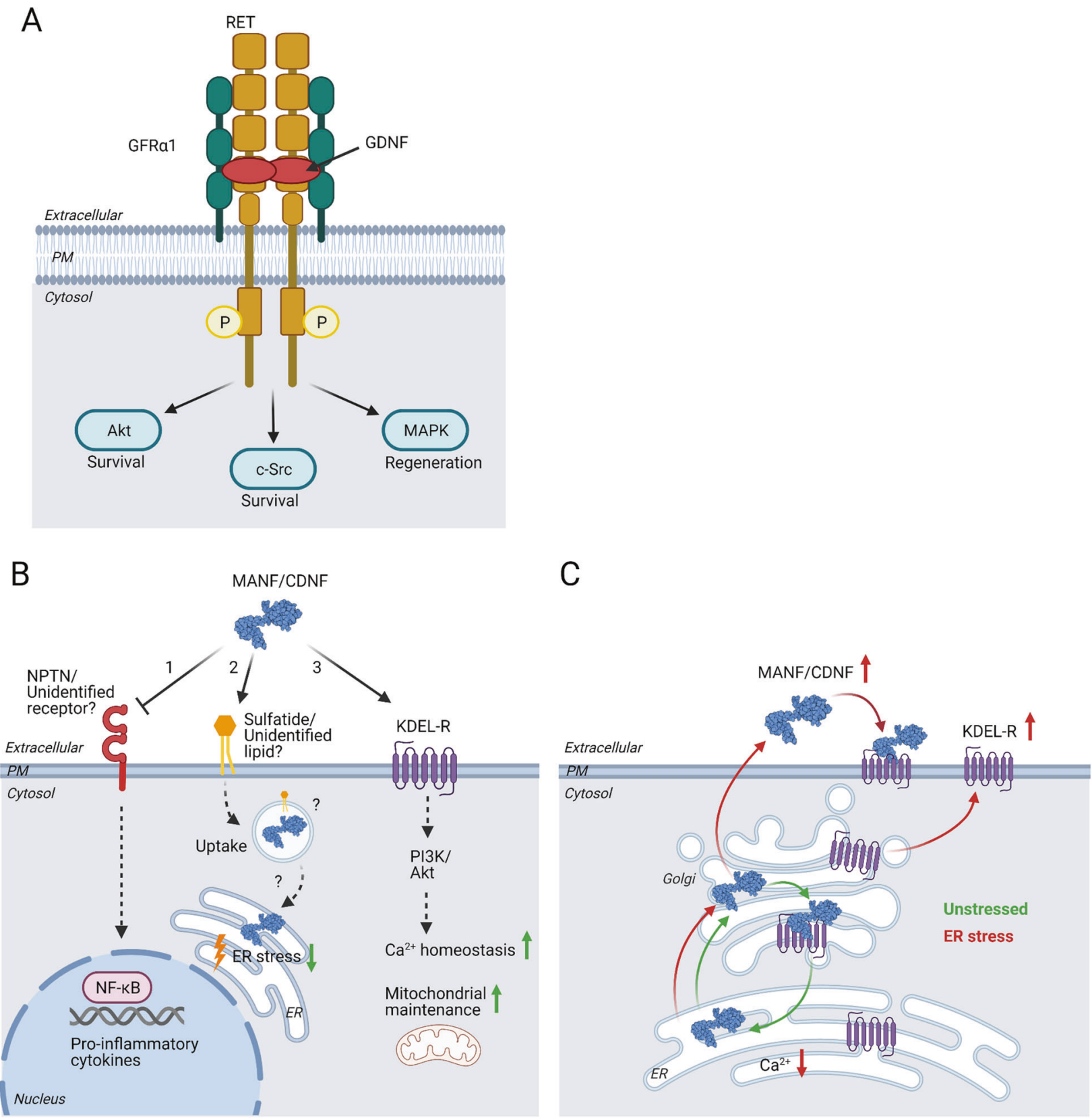

Fig. 3 Plasma membrane receptors of GFLs and MANF/CDNF. A GDNF Family Ligands (GFLs): GDNF; NRTN; artemin; and persephin, function as homodimers to activate transmembrane receptor tyrosine kinase RET. Binding of GFLs to RET is mediated by GDNF family receptor- $\alpha$ (GFR $\alpha 1-4)$ co-receptors, which selectively interact with the GFLs. Ligand binding leads to homodimerization and autophosphorylation of RET, resulting activation of multiple intracellular signaling cascades. GDNF binding to RET is mediated by GFR 1 , and leads to activation of Akt, MAPK and c-Src pathways, promoting neuronal survival and regeneration. B Neuroplastin (NPTN) is a novel receptor for MANF (1). Activation of NPTN induces NF- $\kappa$ B transcription factor and expression of pro-inflammatory cytokines. MANF binding to NPTN decreases proinflammatory response and protects cells against ER stress-induced inflammation and cell death [80]. MANF binds sulfatide (2). Sulfatide is present in the plasma membrane (PM) of neurons and other cell types, suggesting that MANF can interact with sulfatide on the PM. MANF bound to sulfatide can be endocytosed to promote ER homeostasis [32]. The molecular mechanism of the potential endocytosis of MANFsulfatide and subsequent molecular events are unclear. CDNF and MANF may bind to the KDEL-receptor (KDEL-R) on the PM via a C-terminal KDEL-like sequence (3) [36, 67]. Exogenous CDNF promoted calcium homeostasis and mitochondrial maintenance in cardiomyocytes under ER stress conditions by a mechanism dependent on its KDEL-like sequence suggesting that KDEL-R is binding CDNF [67]. The protective effect of CDNF was mediated by PI3K/Akt signaling [67]. C MANF, CDNF, and KDEL-R are induced by ER stress. In unstressed cells, CDNF and MANF are retained in the ER by KDEL-R, whereas in ER stress resulting from the depletion of ER calcium, they are released from cells. In ER stress, KDEL-R possibly localizes to the PM where it may bind extracellular CDNF and MANF.

in dopaminergic, histaminergic, and GABAergic neurotransmitter systems in selective brain areas, indicating that CDNF is important in shaping the structure of neurotransmitter circuits in these fish CNS [82]. In the brain, cdnf deletion led to increased expression of tyrosine hydroxylase 2 which functions in DA synthesis [82]. Alterations in the neurotransmitter networks were associated with abnormal behavior, including impaired social cohesion and anxiety-related risk taking in adult cdnf mutants 

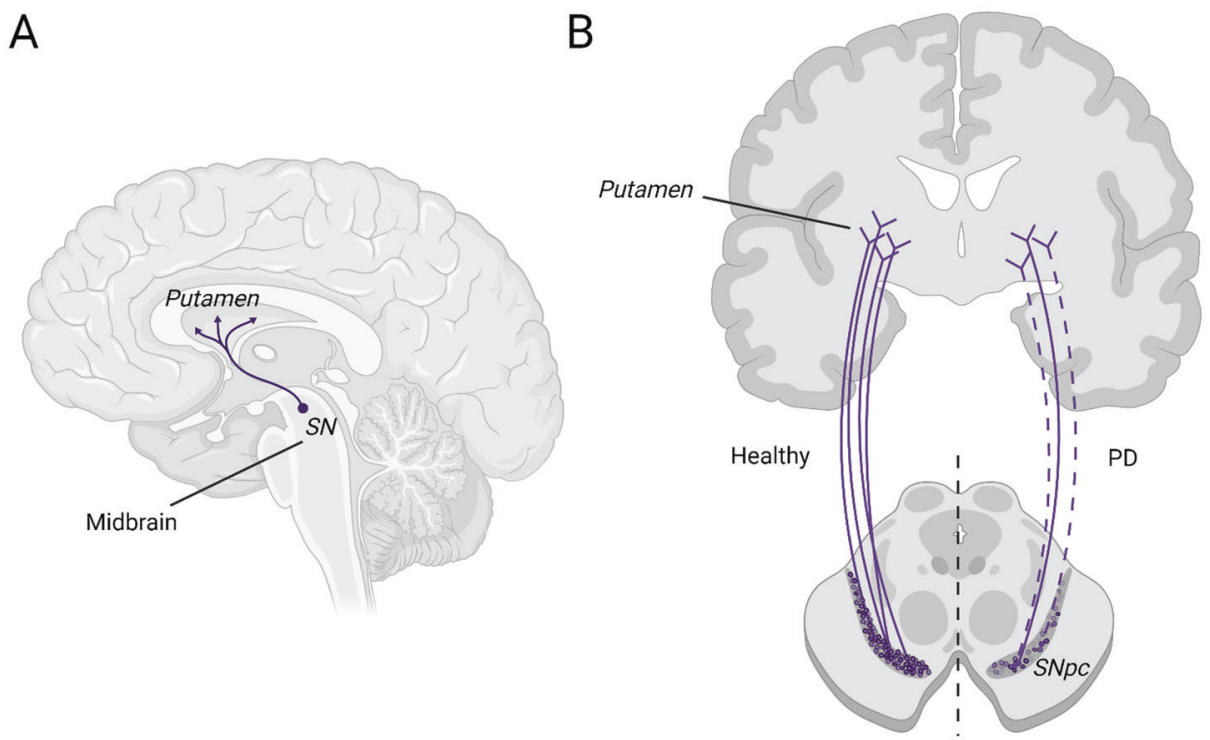

C
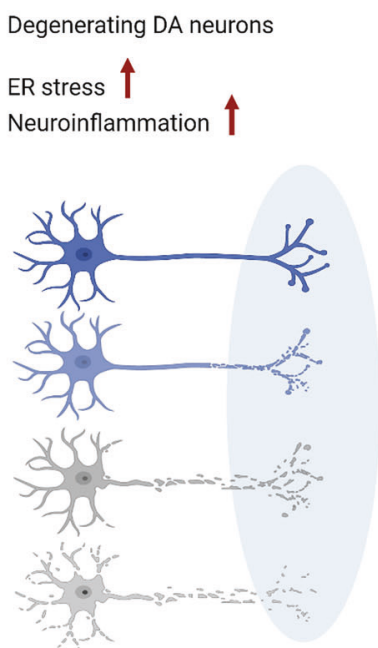

Regenerating DA neurons

$$
\begin{aligned}
& \text { ER stress } \downarrow \\
& \text { Neuroinflammation } \downarrow
\end{aligned}
$$

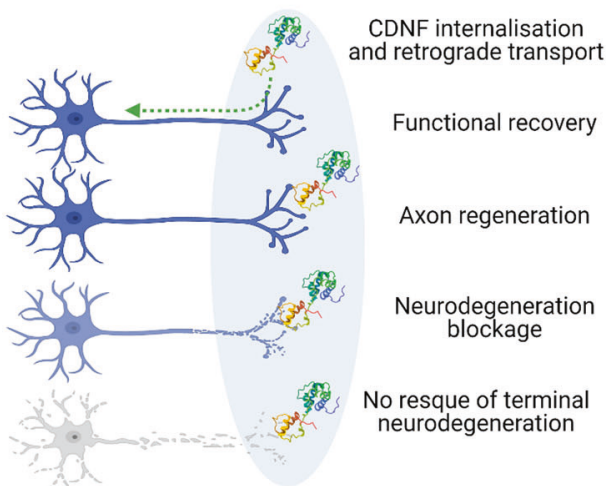

Fig. 4 CDNF promotes survival of dopamine neurons. A Midbrain dopamine (DA) neurons project from substantia nigra (SN) to the putamen forming nigrostriatal pathway. B In Parkinson's disease (PD), midbrain DA neurons degenerate leading to motor and non-motor symptoms. Cell bodies of DA neurons are located in the substantia nigra pars compacta (SNpc). C CDNF prevents neurodegeneration and induces functional recovery of injured DA neurons in animal models of PD. Therapeutic CDNF could reduce ER stress and neuroinflammation that are thought to be involved in the neuropathogenesis of PD. Differently from GDNF, CDNF does not show survival-promoting effects on naive DA neurons.

[82]. Mutant fish were also more susceptible to drug-induced seizures. Interestingly, the observed behavioral phenotypes of cdnf mutant fish are reminiscent of human neuropsychiatric conditions, such as schizophrenia [82], in accordance with the suggested association between a CDNF SNP and schizophrenia susceptibility in humans [91].

Homozygous loss-of-function mutations of the human MANF gene were reported as a cause of childhood diabetes, and were mechanistically connected to ER stress and impaired beta cell function [92]. A homozygous MANF mutation was also associated with mild intellectual disability, microcephaly, and deafness [93], suggesting that MANF has a role in brain development and normal auditory function. In accordance, Manf inactivation in mice resulted in a hearing loss [94]. However, characterization of conventional and CNS-specific Manf knockout mice indicated that endogenous MANF is not required for the maintenance of midbrain DA neurons [95]. CNS-specific deletion of Manf in mice did not affect the number of TH-positive DA neurons in the SNpc, number of dopaminergic fibers in the striatum, or the striatal concentrations of DA or its metabolites in adult mice [95]. Although chronic activation of UPR was detected in the brain tissue of $\mathrm{Manf}^{-1-}$ mice, it did not result in neurodegeneration [95]. In contrast to observations in Manf knockout mice, Drosophila Manf, encoded by a single homolog of human MANF/CDNF, appears to be essential for the maintenance of DA neurites and DA levels in the fly [96]. In DmManf mutant larvae, the volume of DA neurites was diminished whereas somas were maintained, suggesting that DA neurites degenerate before cell bodies [96], thus resembling degeneration of DA neurons in PD. UPR-related genes were upregulated in DmManf mutant embryos indicating ongoing UPR [61]. Larval lethality of DmManf zygotic mutants was rescued with ubiquitously expressed human MANF or CDNF, indicating that DmManf and human MANF and CDNF are functionally conserved [97]. Also in zebrafish, studies of manf knockdown using antisense splice-blocking morpholino oligonucleotides suggested that MANF is involved in the regulation of DA 
neuron development and maintenance [98]. In the manf-1 mutant C. elegans worms neuronal development was normal; however, there was loss of manf- 1 activated ER stress and UPR [59, 60], resembling observations in Manf $^{-1-}$ mice and supporting the role of MANF as a regulator of ER homeostasis.

\section{CDNF effects in animal models of Parkinson's disease}

In patients with $\mathrm{PD}, \mathrm{DA}$ neurons located in the $\mathrm{SN}$ and projecting to the striatum degenerate and die [7] (Fig. 4A, B). In animal models of PD, degeneration of DA neurons can be induced using neurotoxins 6-hydroxydopamine (6-OHDA) and 1-methyl-4-phenyl-1,2,3,6-tetrahydropyridine (MPTP) [99]. In the first in vivo study, a single injection of CDNF before the delivery of 6-OHDA into the striatum significantly reduced amphetamine-induced ipsilateral turning behavior and almost completely protected nigral DA neurons in a rat model of PD [20]. When administered 4 weeks after 6-OHDA, CDNF restored the dopaminergic function and prevented the degeneration of DA neurons at least as efficiently as GDNF [20]. In the following study, the neuroprotective effects of 2-week striatal infusions of CDNF, MANF, and GDNF were compared in a rat 6-OHDA model [84]. CDNF rescued 6-OHDAlesioned nigral DA neurons and TH-positive fibers in the striatum, whereas MANF and GDNF had no significant effect in these measures [84]. The volume of distribution for injected MANF in the striatum was larger than that of CDNF, and both MANF and CDNF diffused significantly better than GDNF $[84,100]$. Intrastriatally injected CDNF similarly to GDNF was retrogradely transported to the SN [84, 101], whereas CDNF injected to SN was not anterogradely transported to the striatum [102].

Airavaara et al. [85] demonstrated that striatal administration of CDNF was neuroprotective and neurorestorative for the THpositive cells in the nigrostriatal DA system in a mouse MPTP model of PD. Jiaming and Niu [103] evaluated the therapeutic effects of CDNF-expressing bone marrow-derived mesenchymal stem cell (MSC) injections. Using intrastriatal, intraventricular, and intravenous routes of CDNF-MSC administration, they showed neurotrophic effects of CDNF-MSC grafts in a rat 6-OHDA model of PD by intrastriatal and intra-lateral ventricular transplantation routes. Since CDNF is mostly an intracellular protein, it was of great interest to test CDNF effects using gene therapy approaches. Bäck and colleagues [86] studied the neuroprotective effect of adeno-associated virus (AAV) serotype 2 vector expressing CDNF in a rat 6-OHDA model of PD. Elevated levels of CDNF expression in the striatum resulted in a marked decrease in amphetamineinduced ipsilateral rotations [86]. However, compared to studies using CDNF protein delivery [20, 84], gene therapy of CDNF provided only partial protection of DA neurons and their fibers [86]. One reason for this can be the retention of CDNF inside the cells with very limited diffusion of CDNF in the striatum [86]. Ren et al. [88] examined the neuroprotective and functional restorative effects of CDNF overexpression in the striatum via gene therapy with an AAV2-CDNF vector in 6-OHDA-lesioned rats. In addition to the significant restoration of $\mathrm{TH}$-immunoreactive nigral neurons and striatal fibers, positron emission tomography (PET) imaging of DA transporters revealed functional recovery of the nigrostriatal DA system [88]. Compared to the study by Bäck et al. [86] the prominent neuroprotection by CDNF in the study by Ren et al. [88] may be ascribed to the optimal expression level and greater spreading of CDNF in the striatum. Hao et al. [104] demonstrated robust long-term overexpression of MANF in rat striatum using AAV9 vector-mediated gene delivery. In a 6-OHDA model of PD, intrastriatal delivery AAV9-MANF provided significant protection for nigral DA neurons and promoted regeneration of striatal DA fibers and increase in striatal DA levels [104]. Striatal MANF overexpression by AAV9 vector led to increased MANF levels also in the $\mathrm{SN}$, suggesting that MANF was retrogradely transported from the striatum to $\mathrm{SN}$, thus providing local protection for nigral neurons [104]. The ability of GDNF and related NTFs to rescue DA neurons in animal models of PD is limited when the neurotoxininduced lesion is severe [5]. Importantly, Wang et al. [105] observed, using a rat 6-OHDA model of PD, that AAV8-CDNF administration significantly improved motor function and increased TH levels in rats with mild 6-OHDA-induced lesions, but it had limited therapeutic effects in rats with severe lesions [105]. Lentiviral vector-mediated overexpression of CDNF or MANF alone in the SN showed differential protection of dopaminergic function in the 6-OHDA model of PD [87]. While overexpression of CDNF in the SN both reduced amphetamine-induced rotational behavior and loss of striatal TH-positive innervation, overexpression of MANF in the SN only protected TH-positive cells in the nigra [87]. However, combined nigral overexpression of CDNF and MANF led to a robust reduction in amphetamine-induced rotations and protection of both DA cells and their fibers, indicating that CDNF and MANF can have synergistic neuroprotective effects [87]. Unfortunately, the levels overexpressed CDNF and MANF in the brain tissue were not reported [87], thus hampering comparisons of their neuroprotective effects. When GDNF was overexpressed in the SN it was unable to direct regeneration of TH-positive axons [106]. Since CDNF is not anterogradely transported from SN to striatum [102], its effects may resemble those of GDNF i.e., have full neuroregenerative potential only when delivered to the striatum. These data indicate that CDNF and MANF have differential modes of action and encourages using a combination of different growth factors for the treatment of PD. Indeed, an additive neurorestorative effect of CDNF and GDNF was demonstrated in the 6-OHDA model of PD in rats [89]. Experiments on cell lines and DA neurons have clearly shown that CDNF and GDNF have completely different modes of action. These additive effects observed in a rat PD model also indicated different mechanisms of action for CDNF and GDNF [89]. Both CDNF and GDNF were able to activate the survival-promoting PI3 kinase-Akt signaling pathway, but only CDNF decreased the levels of ER stress markers ATF6 and BiP, in addition to the level of phosphorylated eukaryotic initiation factor 2 a subunit (elF2a) downstream of the UPR sensor PERK [89]. In 6-OHDA-treated PC12 cells, a cellular model of PD, CDNF treatment increased cell viability through upregulating ratio of anti-apoptotic $\mathrm{BCl}-2 /$ pro-apoptotic Bax proteins and downregulating caspase-3 activity, thus resembling the function of NTFs [107].

Several in vitro studies have indicated that CDNF may provide a novel therapy for neuroinflammation related to the microglia. In microglial cells, CDNF attenuated the production of proinflammatory cytokines prostaglandin E2 and interleukin-1 $\beta$ (IL$1 \beta)$ as well as remarkably suppressed the phosphorylation of c-Jun $\mathrm{N}$-terminal kinase (JNK) [108]. Nadella et al. [109] found that in the 6-OHDA-lesioned rats, CDNF overexpressed from a plasmid vector reduced nitrosative stress, glial markers, and IL- 6 levels in the SN, but not TNFa and IL-1 $\beta$ levels, suggesting that CDNF may be a potential novel agent for the treatment of neuroinflammation seen in the PD.

We still have very limited information about the effects of CDNF on nigral DA neurons in NHPs. CDNF therapeutic effects were first studied in a unilateral 6-OHDA lesion model of PD in marmoset monkeys and compared with the effects of GDNF [110]. This study also monitored the severity of 6-OHDA lesions and treatment effects in vivo using ${ }^{123}$ I-FP-CIT (a DAT ligand) SPECT [110]. This analysis showed a significant increase of DAT binding activity in lesioned monkeys treated with CDNF, whereas no statistical difference was observed in the GDNF-treated group [110]. In a more recent study, CDNF restored SN DA neuron integrity when effects of CDNF and GDNF were compared in a rhesus monkey MPTP model of PD [111]. The animal data together demonstrate that CDNF not only protects but also restores the function of DA neurons by regulating ER stress, neuroinflammation, and counteracting cell death (Fig. 4C). 


\section{First results of clinical trials}

Since the mode of action of CDNF differs from that of GDNF, NRTN, and other growth factors tested in clinical trials for PD, and CDNF was more efficient than GDNF in protecting the function of DA neurons in animal models of PD [84, 110] it was important to test CDNF in clinic. The first clinical Phase I-II, randomized, doubleblind study conducted by Herantis Pharma Plc. investigated the safety and tolerability of intermittent bilateral intraputamenal monthly infusions of CDNF (ClinicalTrials.gov Identifier: NCT03295786) [23, 112]. A two-part study in 17 patients with advanced PD was carried out in three university hospitals in Finland and Sweden. During the initial 6-month period, all patients received either placebo or CDNF at one of two dose levels. This was followed by a 6-month period, in which all patients received CDNF at one of the two dose levels, including the previous placebo group patients. Treatment was administered via a dose delivery system using intraputamenal catheters that were implanted into the putamen at the beginning of the study. Human recombinant CDNF, used in the study, was produced in a mammalian cell line and its biological activity was rigorously tested in neuronal survival assays. Intraputamenal CDNF infusions were safe and well tolerated, and thus the primary endpoint of the study was met. Exploratory endpoints included UPDRS scores and DAT PET, which was performed with a high-resolution research tomography system using DAT radioligand $\left[{ }^{18} \mathrm{~F}\right] \mathrm{FE}-\mathrm{PE} 2 \mathrm{I}$ [113]. A minimal clinical important difference in Unified Parkinson's Disease Rating Scale (UPDRS III) (off) was observed in the CDNF dose-groups suggesting a potential slowing of disease progression. Furthermore, increased DAT availability in the putamen was observed with PET in some patients that received CDNF suggesting a potential improvement in dopaminergic function. Although the study of patient population with advanced PD was not designed to show efficacy of CDNF, the documented improvements in some patients were very encouraging [112].

\section{Concluding remarks}

CDNF is an atypical neurotrophic protein that is cytoprotective both in the ER and as an extracellular factor. In addition to neuroprotective and neuroregenerative activities that, similarly to other NTFs, partially occur via the activation of PI3 kinase-Akt pathways [89, 114], CDNF also counteracts cell death by regulating UPR pathways in the ER [70,89]. CDNF protects against toxicity of aSyn oligomers in vitro [30], and was recently shown to directly interact with aSyn, reduce propagation of aSyn aggregation and alleviate behavioral deficits induced by aSyn fibrils in mice [115]. CDNF also reduces the synthesis and release of pro-inflammatory cytokines decreasing neuroinflammation [108, 109, 114, 116]. One particularly interesting property of CDNF, which differentiates it from classical NTFs, is that its effects on naive and healthy neurons are low or even absent $[20,29,63]$. This may be very important from the clinical point of view, because it suggests a good safety profile for CDNF. Although CDNF has now been successfully tested in rodent and NHP models of PD [20, 76, 84-86, 88, 103, 109$111,117-119]$, as well as in Phase I-II clinical trial in patients with PD $[23,112]$, several challenges remain. CDNF can regulate UPR pathways, but its receptors and signaling pathways remain poorly described. We also know very little about how CDNF acts in the ER, how it is secreted and whether it has both intracellular and plasma membrane receptors. Despite the promising results in animal models of PD, NTF- and CDNF-based treatments share a fundamental drawback; they require a direct delivery of the therapeutic protein to the brain through invasive surgery, since NTFs and CDNF cannot pass through the BBB. We have recently discovered a novel CDNF variant that acts similarly to CDNF, but can efficiently pass through the BBB [28]. Furthermore, our preliminary data show that this CDNF variant has beneficial effects in both rodent 6-OHDA and MPTP toxin models of PD when administered subcutaneously [28]. Although these data are encouraging, much more work is needed before BBB-penetrating CDNF-derived molecules can be taken to clinical trials. One important reason for the limited success of clinical development of NTFs so far is their poor pharmacokinetic characteristics, which include inability to cross tissue barriers, poor diffusion in tissues, ability to activate several receptors in different tissues and cell types, and high costs of the drug [5]. The development of small molecules selectively targeting CDNF receptors with optimized pharmacokinetic properties can open a new avenue for the development of disease-modifying treatments of neurodegenerative diseases in the future.

CDNF was also shown to have beneficial effects in animal models of Alzheimer's disease [120], amyotrophic lateral sclerosis [121], and Huntington's disease [122]. However, further studies are required to confirm these exciting results. Taken together, unique properties of CDNF encourage its testing in different neurological diseases, especially in those where neuronal protein homeostasis has been perturbed.

\section{REFERENCES}

1. Tysnes $O B$, Storstein A. Epidemiology of Parkinson's disease. J Neural Transm (Vienna). 2017;124:901-5.

2. Dorsey ER, Bloem BR. The Parkinson pandemic-a call to action. JAMA Neurol. 2018;75:9-10.

3. Cheng HC, Ulane CM, Burke RE. Clinical progression in Parkinson disease and the neurobiology of axons. Ann Neurol. 2010;67:715-25.

4. Schapira AHV, Chaudhuri KR, Jenner P. Non-motor features of Parkinson disease. Nat Rev Neurosci. 2017;18:509.

5. Sidorova YA, Saarma M. Can growth factors cure Parkinson's disease? Trends Pharm Sci. 2020;41:909-22.

6. Allen SJ, Watson JJ, Shoemark DK, Barua NU, Patel NK. GDNF, NGF and BDNF as therapeutic options for neurodegeneration. Pharm Ther. 2013;138:155-75.

7. Poewe W, Seppi K, Tanner CM, Halliday GM, Brundin P, Volkmann J, et al. Parkinson disease. Nat Rev Dis Prim. 2017;3:17013.

8. Mercado G, Valdes P, Hetz C. An ERcentric view of Parkinson's disease. Trends Mol Med. 2013;19:165-75.

9. Colla E. Linking the endoplasmic reticulum to Parkinson's disease and alphasynucleinopathy. Front Neurosci. 2019;13:560.

10. Wakabayashi K, Tanji K, Odagiri S, Miki Y, Mori F, Takahashi H. The Lewy body in Parkinson's disease and related neurodegenerative disorders. Mol Neurobiol. 2013;47:495-508

11. Airaksinen MS, Saarma M. The GDNF family: signalling, biological functions and therapeutic value. Nat Rev Neurosci. 2002;3:383-94.

12. Huang EJ, Reichardt LF. Neurotrophins: roles in neuronal development and function. Annu Rev Neurosci. 2001;24:677-736.

13. Kirkeby A, Barker RA. Parkinson disease and growth factors - is GDNF good enough? Nat Rev Neurol. 2019;15:312-4.

14. Manfredsson FP, Polinski NK, Subramanian T, Boulis N, Wakeman DR, Mandel RJ. The future of GDNF in Parkinson's disease. Front Aging Neurosci. 2020;12:593572.

15. Decressac M, Ulusoy A, Mattsson B, Georgievska B, Romero-Ramos M, Kirik D, et al. GDNF fails to exert neuroprotection in a rat alpha-synuclein model of Parkinson's disease. Brain 2011;134:2302-11.

16. Chmielarz P, Er S, Konovalova J, Bandres L, Hlushchuk I, Albert K, et al. GDNF/RET signaling pathway activation eliminates Lewy body pathology in midbrain dopamine neurons. Mov Disord. 2020;35:2279-89.

17. Lang AE, Gill S, Patel NK, Lozano A, Nutt JG, Penn R, et al. Randomized controlled trial of intraputamenal glial cell line-derived neurotrophic factor infusion in Parkinson disease. Ann Neurol. 2006;59:459-66.

18. Olanow CW, Bartus RT, Volpicelli-Daley LA, Kordower JH. Trophic factors for Parkinson's disease: to live or let die. Mov Disord. 2015;30:1715-24.

19. Kordower JH, Bjorklund A. Trophic factor gene therapy for Parkinson's disease. Mov Disord. 2013;28:96-109.

20. Lindholm P, Voutilainen MH, Lauren J, Peranen J, Leppanen VM, Andressoo JO, et al. Novel neurotrophic factor CDNF protects and rescues midbrain dopamine neurons in vivo. Nature 2007;448:73-7.

21. Petrova P, Raibekas A, Pevsner J, Vigo N, Anafi M, Moore MK, et al. MANF: a new mesencephalic, astrocyte-derived neurotrophic factor with selectivity for dopaminergic neurons. J Mol Neurosci. 2003;20:173-88.

22. Albert K, Airavaara M. Neuroprotective and reparative effects of endoplasmic reticulum luminal proteins - mesencephalic astrocyte-derived neurotrophic factor and cerebral dopamine neurotrophic factor. Croat Med J. 2019;60:99-108. 
23. Huttunen HJ, Saarma M. CDNF protein therapy in Parkinson's disease. Cell Transplant. 2019;28:349-66.

24. Jantti M, Harvey BK. Trophic activities of endoplasmic reticulum proteins CDNF and MANF. Cell Tissue Res. 2020;382:83-100.

25. Kim Y, Park SJ, Chen YM. Mesencephalic astrocyte-derived neurotrophic factor (MANF), a new player in endoplasmic reticulum diseases: structure, biology, and therapeutic roles. Transl Res. 2017;188:1-9.

26. Lindahl M, Saarma M, Lindholm P. Unconventional neurotrophic factors CDNF and MANF: structure, physiological functions and therapeutic potential. Neurobiol Dis. 2017;97:90-102.

27. Sousa-Victor $P$, Jasper $H$, Neves J. Trophic factors in inflammation and regeneration: the role of MANF and CDNF. Front Physiol. 2018;9:1629.

28. Saarma M, Voutilainen MH, Airavaara M, Yu LY, Lindahl M. C-terminal CDNF and MANF fragments, pharmaceutical compositions comprising same and uses thereof. United States Patent Application No 2019;17/043028; 2018.

29. Hellman M, Arumae U, Yu LY, Lindholm P, Peranen J, Saarma M, et al. Mesencephalic astrocyte-derived neurotrophic factor (MANF) has a unique mechanism to rescue apoptotic neurons. J Biol Chem. 2011;286:2675-80.

30. Latge C, Cabral KM, de Oliveira GA, Raymundo DP, Freitas JA, Johanson L, et al. The solution structure and dynamics of full-length human cerebral dopamine neurotrophic factor and its neuroprotective role against alpha-synuclein oligomers. J Biol Chem. 2015;290:20527-40.

31. Parkash V, Lindholm P, Peranen J, Kalkkinen N, Oksanen E, Saarma M, et al. The structure of the conserved neurotrophic factors MANF and CDNF explains why they are bifunctional. Protein Eng Des Sel. 2009;22:233-41.

32. Bai M, Vozdek R, Hnizda A, Jiang C, Wang B, Kuchar L, et al. Conserved roles of $C$. elegans and human MANFs in sulfatide binding and cytoprotection. Nat Commun. 2018;9:897.

33. Matlik K, Yu LY, Eesmaa A, Hellman M, Lindholm P, Peranen J, et al. Role of two sequence motifs of mesencephalic astrocyte-derived neurotrophic factor in its survival-promoting activity. Cell Death Dis. 2015;6:e2032.

34. Norisada J, Hirata Y, Amaya F, Kiuchi K, Oh-hashi K. A comparative analysis of the molecular features of MANF and CDNF. PLoS ONE. 2016;11:e0146923.

35. Oh-Hashi K, Tanaka K, Koga H, Hirata Y, Kiuchi K. Intracellular trafficking and secretion of mouse mesencephalic astrocyte-derived neurotrophic factor. Mol Cell Biochem. 2012;363:35-41.

36. Henderson MJ, Richie CT, Airavaara M, Wang Y, Harvey BK. Mesencephalic astrocyte-derived neurotrophic factor (MANF) secretion and cell surface binding are modulated by KDEL receptors. J Biol Chem. 2013;288:4209-25.

37. Galli E, Lindholm P, Kontturi LS, Saarma M, Urtti A, Yliperttula M. Characterization of CDNF-secreting ARPE-19 cell clones for encapsulated cell therapy. Cell Transplant. 2019;4:413-24.

38. Sun ZP, Gong L, Huang SH, Geng Z, Cheng L, Chen ZY. Intracellular trafficking and secretion of cerebral dopamine neurotrophic factor in neurosecretory cells. J Neurochem. 2011;117:121-32.

39. Mizobuchi N, Hoseki J, Kubota H, Toyokuni S, Nozaki J, Naitoh M, et al. ARMET is a soluble ER protein induced by the unfolded protein response via ERSE-II element. Cell Struct Funct. 2007;32:41-50.

40. Fernandez A, Guzman S, Cruz Y, Zamorano P. Construction of bicistronic lentiviral vectors for tracking the expression of CDNF in transduced cells. Plasmid 2014;76:15-23.

41. Walter $P$, Ron $D$. The unfolded protein response: from stress pathway to homeostatic regulation. Science 2011;334:1081-6.

42. Harding HP, Zhang Y, Ron D. Protein translation and folding are coupled by an endoplasmic-reticulum-resident kinase. Nature 1999;397:271-4.

43. Bertolotti A, Zhang Y, Hendershot LM, Harding HP, Ron D. Dynamic interaction of BiP and ER stress transducers in the unfolded-protein response. Nat Cell Biol. 2000;2:326-32.

44. Haze $\mathrm{K}$, Yoshida $\mathrm{H}$, Yanagi $\mathrm{H}$, Yura $\mathrm{T}$, Mori $\mathrm{K}$. Mammalian transcription factor ATF6 is synthesized as a transmembrane protein and activated by proteolysis in response to endoplasmic reticulum stress. Mol Biol Cell. 1999; 10:3787-99.

45. Sano R, Reed JC. ER stress-induced cell death mechanisms. Biochim Biophys Acta. 2013;1833:3460-70.

46. Baek JH, Whitfield D, Howlett D, Francis P, Bereczki E, Ballard C, et al. Unfolded protein response is activated in Lewy body dementias. Neuropathol Appl Neurobiol. 2016;42:352-65.

47. Hetz C, Saxena S. ER stress and the unfolded protein response in neurodegeneration. Nat Rev Neurol. 2017;13:477-91.

48. Hoozemans JJ, van Haastert ES, Eikelenboom P, de Vos RA, Rozemuller JM, Scheper W. Activation of the unfolded protein response in Parkinson's disease. Biochem Biophys Res Commun. 2007;354:707-11.

49. Danilova T, Galli E, Pakarinen E, Palm E, Lindholm P, Saarma M, et al. Mesencephalic astrocyte-derived neurotrophic factor (MANF) is highly expressed in mouse tissues with metabolic function. Front Endocrinol. 2019;10:765.
50. Lindholm P, Peranen J, Andressoo JO, Kalkkinen N, Kokaia Z, Lindvall O, et al. MANF is widely expressed in mammalian tissues and differently regulated after ischemic and epileptic insults in rodent brain. Mol Cell Neurosci. 2008;39:356-71.

51. Lee AH, Iwakoshi NN, Glimcher LH. XBP-1 regulates a subset of endoplasmic reticulum resident chaperone genes in the unfolded protein response. Mol Cell Biol. 2003;23:7448-59.

52. Wang D, Hou C, Cao Y, Cheng Q, Zhang L, Li H, et al. XBP1 activation enhances MANF expression via binding to endoplasmic reticulum stress response elements within MANF promoter region in hepatitis B. Int J Biochem Cell Biol. 2018;99:140-6.

53. Hartley CL, Edwards S, Mullan L, Bell PA, Fresquet M, Boot-Handford RP, et al. Armet/Manf and Creld2 are components of a specialized ER stress response provoked by inappropriate formation of disulphide bonds: implications for genetic skeletal diseases. Hum Mol Genet. 2013;22:5262-75.

54. Tadimalla A, Belmont PJ, Thuerauf DJ, Glassy MS, Martindale JJ, Gude N, et al. Mesencephalic astrocyte-derived neurotrophic factor is an ischemia-inducible secreted endoplasmic reticulum stress response protein in the heart. Circ Res. 2008;103:1249-58.

55. Yu YQ, Liu LC, Wang FC, Liang Y, Cha DQ, Zhang JJ, et al. Induction profile of MANF/ARMET by cerebral ischemia and its implication for neuron protection. J Cereb Blood Flow Metab. 2010;30:79-91.

56. Danilova T, Belevich I, Li H, Palm E, Jokitalo E, Otonkoski T, et al. MANF is required for the postnatal expansion and maintenance of pancreatic beta-cell mass in mice. Diabetes 2019;68:66-80.

57. Lindahl M, Danilova T, Palm E, Lindholm P, Voikar V, Hakonen E, et al. MANF is indispensable for the proliferation and survival of pancreatic beta cells. Cell Rep. 2014;7:366-75.

58. Apostolou A, Shen Y, Liang Y, Luo J, Fang S. Armet, a UPR-upregulated protein, inhibits cell proliferation and ER stress-induced cell death. Exp Cell Res. 2008;314:2454-67.

59. Hartman JH, Richie $C T$, Gordon KL, Mello DF, Castillo P, Zhu A, et al. MANF deletion abrogates early larval Caenorhabditis elegans stress response to tunicamycin and Pseudomonas aeruginosa. Eur J Cell Biol. 2019;98:151043.

60. Richman C, Rashid S, Prashar S, Mishra R, Selvaganapathy PR, Gupta BP. C. elegans MANF homolog is necessary for the protection of dopaminergic neurons and ER unfolded protein response. Front Neurosci. 2018;12:544.

61. Palgi M, Greco D, Lindstrom R, Auvinen P, Heino TI. Gene expression analysis of Drosophilaa Manf mutants reveals perturbations in membrane traffic and major metabolic changes. BMC Genomics. 2012;13:134.

62. Glembotski CC, Thuerauf DJ, Huang C, Vekich JA, Gottlieb RA, Doroudgar S. Mesencephalic astrocyte-derived neurotrophic factor protects the heart from ischemic damage and is selectively secreted upon sarco/endoplasmic reticulum calcium depletion. J Biol Chem. 2012;287:25893-904.

63. Eesmaa A, Yu LY, Goos H, Noges K, Kovaleva V, Hellman M, et al. The cytoprotective protein MANF promotes neuronal survival independently from its role as a GRP78 cofactor. J Biol Chem. 2021;296:100295.

64. Yan Y, Rato C, Rohland L, Preissler S, Ron D. MANF antagonizes nucleotide exchange by the endoplasmic reticulum chaperone BiP. Nat Commun. 2019;10:541.

65. Kovaleva V, Yu L-Y, Ivanova L, Nam J, Eesmaa A, Kumpula E-P, et al. MANF regulates unfolded protein response and neuronal survival through its ERlocated receptor IRE1a. bioRxiv: 2020:2020.09.22.307744 [Preprint]. 2020. Available from: https://www.biorxiv.org/content/10.1101/2020.09.22.307744v1.

66. Arrieta A, Blackwood EA, Stauffer WT, Santo Domingo M, Bilal AS, Thuerauf DJ, et al. Mesencephalic astrocyte-derived neurotrophic factor is an ER-resident chaperone that protects against reductive stress in the heart. J Biol Chem. 2020;295:7566-83.

67. Maciel L, de Oliveira DF, Mesquita F, Souza H, Oliveira L, Christie MLA, et al. New cardiomyokine reduces myocardial ischemia/reperfusion injury by PI3K-AKT pathway via a putative KDEL-receptor binding. J Am Heart Assoc. 2021;10:e019685.

68. Zhang GL, Wang LH, Liu XY, Zhang YX, Hu MY, Liu L, et al. Cerebral dopamine neurotrophic factor (CDNF) has neuroprotective effects against cerebral ischemia that may occur through the endoplasmic reticulum stress pathway. Int J Mol Sci. 2018;19:1905.

69. Liu H, Yu C, Yu H, Zhong L, Wang Y, Liu J, et al. Cerebral dopamine neurotrophic factor protects H9c2 cardiomyocytes from apoptosis. Herz 2018;43:346-51.

70. Arancibia D, Zamorano $P$, Andres ME. CDNF induces the adaptive unfolded protein response and attenuates endoplasmic reticulum stress-induced cell death. Biochim Biophys Acta Mol Cell Res. 2018;1865:1579-89.

71. Cheng L, Zhao H, Zhang W, Liu B, Liu Y, Guo Y, et al. Overexpression of conserved dopamine neurotrophic factor (CDNF) in astrocytes alleviates endoplasmic reticulum stress-induced cell damage and inflammatory cytokine secretion. Biochem Biophys Res Commun. 2013;435:34-9.

72. Galli $E$, Härkönen $T$, Sainio MT, Ustav $M$, Toots $U$, Urtti $A$, et al. Increased circulating concentrations of mesencephalic astrocyte-derived neurotrophic factor in children with type 1 diabetes. Sci Rep. 2016;6:29058. 
73. Galli E, Planken A, Kadastik-Eerme L, Saarma M, Taba P, Lindholm P. Increased serum levels of mesencephalic astrocyte-derived neurotrophic factor in subjects with Parkinson's disease. Front Neurosci. 2019;13:929.

74. Sousa-Victor P, Neves J, Cedron-Craft W, Ventura PB, Liao CY, Riley RR, et al. MANF regulates metabolic and immune homeostasis in ageing and protects against liver damage. Nat Metab. 2019;1:276-90.

75. Chalazonitis A, Li Z, Pham TD, Chen J, Rao M, Lindholm P, et al. Cerebral dopamine neurotrophic factor is essential for enteric neuronal development, maintenance, and regulation of gastrointestinal transit. J Comp Neurol. 2020;528:2420-44.

76. Jaumotte JD, Saarma M, Zigmond MJ. Protection of dopamine neurons by CDNF and neurturin variant N4 against MPP+ in dissociated cultures from rat mesencephalon. PLoS ONE. 2021;16:e0245663.

77. Zhou W, Chang L, Fang Y, Du Z, Li Y, Song Y, et al. Cerebral dopamine neurotrophic factor alleviates Abeta25-35-induced endoplasmic reticulum stress and early synaptotoxicity in rat hippocampal cells. Neurosci Lett. 2016;633:40-6.

78. Hakonen E, Chandra V, Fogarty CL, Yu NY, Ustinov J, Katayama S, et al. MANF protects human pancreatic beta cells against stress-induced cell death. Diabetologia 2018;61:2202-14.

79. Eizirik DL, Cardozo AK, Cnop M. The role for endoplasmic reticulum stress in diabetes mellitus. Endocr Rev. 2008;29:42-61.

80. Yagi T, Asada R, Kanekura K, Eesmaa A, Lindahl M, Saarma M, et al. Neuroplastin modulates anti-inflammatory effects of MANF. iScience. 2020;23:101810.

81. Virachit S, Mathews KJ, Cottam V, Werry E, Galli E, Rappou E, et al. Levels of glial cell line-derived neurotrophic factor are decreased, but fibroblast growth factor 2 and cerebral dopamine neurotrophic factor are increased in the hippocampus in parkinson's disease. Brain Pathol. 2019;29:813-25.

82. Chen YC, Baronio D, Semenova S, Abdurakhmanova S, Panula P. Cerebral dopamine neurotrophic factor regulates multiple neuronal subtypes and behavior. J Neurosci. 2020;40:6146-64.

83. Lindahl M, Chalazonitis A, Palm E, Pakarinen E, Danilova T, Pham TD, et al. Cerebral dopamine neurotrophic factor-deficiency leads to degeneration of enteric neurons and altered brain dopamine neuronal function in mice. Neurobiol Dis. 2020;134:104696.

84. Voutilainen $\mathrm{MH}$, Back S, Peranen J, Lindholm P, Raasmaja A, Mannisto PT, et al. Chronic infusion of CDNF prevents 6-OHDA-induced deficits in a rat model of Parkinson's disease. Exp Neurol. 2011;228:99-108.

85. Airavaara M, Harvey BK, Voutilainen $\mathrm{MH}$, Shen $\mathrm{H}$, Chou J, Lindholm $\mathrm{P}$, et al. CDNF protects the nigrostriatal dopamine system and promotes recovery after MPTP treatment in mice. Cell Transplant. 2012;21:1213-23.

86. Back S, Peranen J, Galli E, Pulkkila P, Lonka-Nevalaita L, Tamminen T, et al. Gene therapy with AAV2-CDNF provides functional benefits in a rat model of Parkinson's disease. Brain Behav. 2013;3:75-88.

87. Cordero-Llana O, Houghton BC, Rinaldi F, Taylor H, Yanez-Munoz RJ, Uney JB, et al. Enhanced efficacy of the CDNF/MANF family by combined intranigral overexpression in the 6-OHDA rat model of Parkinson's disease. Mol Ther. 2015;23:244-54.

88. Ren X, Zhang T, Gong X, Hu G, Ding W, Wang X. AAV2-mediated striatum delivery of human CDNF prevents the deterioration of midbrain dopamine neurons in a 6-hydroxydopamine induced parkinsonian rat model. Exp Neurol. 2013;248:148-56.

89. Voutilainen $M H$, De Lorenzo F, Stepanova $P$, Back S, Yu LY, Lindholm $P$, et al. Evidence for an additive neurorestorative effect of simultaneously administered CDNF and GDNF in hemiparkinsonian rats: implications for different mechanism of action. eNeuro. 2017;4:ENEURO.0117-16.2017.

90. Choi JM, Hong JH, Chae MJ, Ngyuen PH, Kang HS, Ma HI, et al. Analysis of mutations and the association between polymorphisms in the cerebral dopamine neurotrophic factor (CDNF) gene and Parkinson disease. Neurosci Lett. 2011;493:97-101.

91. Yang Y, Yu H, Li W, Liu B, Zhang H, Ding S, et al. Association between cerebral dopamine neurotrophic factor (CDNF) 2 polymorphisms and schizophrenia susceptibility and symptoms in the Han Chinese population. Behav Brain Funct. 2018;14:1.

92. Montaser H, Patel KA, Balboa D, Ibrahim H, Lithovius V, Naatanen A, et al. Loss of MANF causes childhood-onset syndromic diabetes due to increased endoplasmic reticulum stress. Diabetes 2021;70:1006-18.

93. Yavarna T, Al-Dewik N, Al-Mureikhi M, Ali R, Al-Mesaifri F, Mahmoud L, et al. High diagnostic yield of clinical exome sequencing in Middle Eastern patients with Mendelian disorders. Hum Genet. 2015;134:967-80.

94. Herranen A, Ikaheimo K, Lankinen T, Pakarinen E, Fritzsch B, Saarma M, et al. Deficiency of the ER-stress-regulator MANF triggers progressive outer hair cell death and hearing loss. Cell Death Dis. 2020;11:100.

95. Pakarinen E, Danilova T, Voikar V, Chmielarz P, Piepponen P, Airavaara M, et al. MANF ablation causes prolonged activation of the UPR without neurodegeneration in the mouse midbrain dopamine system. eNeuro. 2020;7:ENEURO.0477-19.2019.
96. Palgi M, Lindstrom R, Peranen J, Piepponen TP, Saarma M, Heino TI. Evidence that DmMANF is an invertebrate neurotrophic factor supporting dopaminergic neurons. Proc Natl Acad Sci USA. 2009;106:2429-34.

97. Lindstrom $R$, Lindholm $P$, Kallijarvi J, Yu LY, Piepponen TP, Arumae $U$, et al. Characterization of the structural and functional determinants of MANF/CDNF in Drosophila in vivo model. PLoS ONE. 2013;8:e73928.

98. Chen YC, Sundvik M, Rozov S, Priyadarshini M, Panula P. MANF regulates dopaminergic neuron development in larval zebrafish. Dev Biol. 2012;370:237-49.

99. Airavaara M, Parkkinen I, Konovalova J, Albert K, Chmielarz P, Domanskyi A. Back and to the future: from neurotoxin-induced to human Parkinson's disease models. Curr Protoc Neurosci. 2020;91:e88.

100. Voutilainen $M H$, Back S, Porsti E, Toppinen L, Lindgren L, Lindholm $P$, et al. Mesencephalic astrocyte-derived neurotrophic factor is neurorestorative in rat model of Parkinson's disease. J Neurosci. 2009;29:9651-9.

101. Matlik K, Vihinen $\mathrm{H}$, Bienemann A, Palgi J, Voutilainen $\mathrm{MH}$, Booms $\mathrm{S}$, et al. Intrastriatally infused exogenous CDNF is endocytosed and retrogradely transported to substantia nigra. eNeuro. 2017;4:ENEURO.0128-16.2017.

102. Albert K, Renko JM, Matlik K, Airavaara M, Voutilainen MH. Cerebral dopamine neurotrophic factor diffuses around the brainstem and does not undergo anterograde transport after injection to the substantia nigra. Front Neurosci. 2019;13:590.

103. Jiaming M, Niu C. Comparing neuroprotective effects of CDNF-expressing bone marrow derived mesenchymal stem cells via differing routes of administration utilizing an in vivo model of Parkinson's disease. Neurol Sci. 2015;36:281-7.

104. Hao F, Yang C, Chen SS, Wang YY, Zhou W, Hao Q, et al. Long-term protective effects of AAV9-mesencephalic astrocyte-derived neurotrophic factor gene transfer in parkinsonian rats. Exp Neurol. 2017;291:120-33.

105. Wang L, Wang Z, Zhu R, Bi J, Feng X, Liu W, et al. Therapeutic efficacy of AAV8mediated intrastriatal delivery of human cerebral dopamine neurotrophic factor in 6-OHDA-induced parkinsonian rat models with different disease progression. PLoS ONE. 2017;12:e0179476.

106. Kirik D, Rosenblad C, Bjorklund A, Mandel RJ. Long-term rAAV-mediated gene transfer of GDNF in the rat Parkinson's model: intrastriatal but not intranigral transduction promotes functional regeneration in the lesioned nigrostriatal system. J Neurosci. 2000;20:4686-700.

107. Mei JM, Niu CS. Effects of CDNF on 6-OHDA-induced apoptosis in PC12 cells via modulation of Bcl-2/Bax and caspase-3 activation. Neurol Sci. 2014;35:1275-80.

108. Zhao H, Cheng L, Liu Y, Zhang W, Maharjan S, Cui Z, et al. Mechanisms of antiinflammatory property of conserved dopamine neurotrophic factor: inhibition of JNK signaling in lipopolysaccharide-induced microglia. J Mol Neurosci. 2014;52:186-92.

109. Nadella R, Voutilainen MH, Saarma M, Gonzalez-Barrios JA, Leon-Chavez BA, Jimenez JM, et al. Transient transfection of human CDNF gene reduces the 6hydroxydopamine-induced neuroinflammation in the rat substantia nigra. J Neuroinflammation. 2014;11:209.

110. Garea-Rodriguez E, Eesmaa A, Lindholm P, Schlumbohm C, Konig J, Meller B, et al. Comparative analysis of the effects of neurotrophic factors CDNF and GDNF in a nonhuman primate model of Parkinson's disease. PLoS ONE. 2016;11:e0149776.

111. Ganapathy Subramanian K, Dettmer A, Rockcastle N, Zhang Z, Doyle A, Noorbaksh $A$, et al. Intraputamenal CDNF infusions restore substantia nigra dopamine neuron integrity in the monkey low-dose MPTP model of Parkinson's disease. Society for Neuroscience Annual Meeting. Presentation 331:07/L3. 2013.

112. Huttunen $\mathrm{HJ}$, Booms S, Kerstens V, Fazio P, Johansson J, Koskinen J, et al. Phase I-II first-in-man clinical trial of intraputamenal CDNF in Parkinson's disease: topline results of the 12-month treatment period. AD/PD ${ }^{\mathrm{TM}}$ Abstract. 2021.

113. Stepanov V, Krasikova R, Raus L, Loog O, Hiltunen J, Halldin C. An efficient onestep radiosynthesis of [18F]FE-PE2I, a PET radioligand for imaging of dopamine transporters. J Label Compd Radiopharm. 2012;55:206-10.

114. Zhang $Y$, Xiang $Y$, Wang $X$, Zhu L, Li H, Wang S, et al. Cerebral dopamine neurotrophic factor protects microglia by combining with AKT and by regulating FoxO1/mTOR signaling during neuroinflammation. Biomed Pharmacother. 2019;109:2278-84.

115. Albert K, Raymundo DP, Panhelainen A, Eesmaa A, Shvachiy L, Araujo GR, et al. Cerebral dopamine neurotrophic factor reduces alpha-synuclein aggregation and propagation and alleviates behavioral alterations in vivo. Mol Ther. 2021;29:2821-40.

116. Zhao H, Cheng L, Du X, Hou Y, Liu Y, Cui Z, et al. Transplantation of cerebral dopamine neurotrophic factor transducted BMSCs in contusion spinal cord injury of rats: promotion of nerve regeneration by alleviating neuroinflammation. Mol Neurobiol. 2016;53:187-99.

117. Huotarinen A, Penttinen AM, Back S, Voutilainen MH, Julku U, Piepponen TP, et al. Combination of CDNF and deep brain stimulation decreases neurological deficits in late-stage model Parkinson's disease. Neuroscience 2018;374:250-63.

118. Mei J, Niu C. Effects of engineered conserved dopamine neurotrophic factorexpressing bone marrow stromal cells on dopaminergic neurons following 6-OHDA administrations. Mol Med Rep. 2015;11:1207-13. 
119. Wang L, Wang Z, Xu X, Zhu R, Bi J, Liu W, et al. Recombinant AAV8-mediated intrastriatal gene delivery of CDNF protects rats against methamphetamine neurotoxicity. Int J Med Sci. 2017;14:340-7.

120. Kemppainen $S$, Lindholm $P$, Galli E, Lahtinen HM, Koivisto $H$, Hamalainen $E$, et al. Cerebral dopamine neurotrophic factor improves long-term memory in APP/ PS1 transgenic mice modeling Alzheimer's disease as well as in wild-type mice. Behav Brain Res. 2015;291:1-11.

121. De Lorenzo $F$, Lüningschrör $P$, Nam J, Pilotto $F$, Galli $E$, Lindholm $P$, et al. CDNF rescues motor neurons in three animal models of ALS by targeting ER stress. bioRxiv: 2020.05.05.078618 [Preprint]. 2020. Available from: https://www.biorxiv. org/content/10.1101/2020.05.05.078618v2.

122. Stepanova $P$, Srinivasan V, Lindholm D, Voutilainen $M H$. Cerebral dopamine neurotrophic factor (CDNF) protects against quinolinic acid-induced toxicity in in vitro and in vivo models of Huntington's disease. Sci Rep. 2020;10:19045.

123. Kotzbauer PT, Lampe PA, Heuckeroth RO, Golden JP, Creedon DJ, Johnson EM Jr., et al. Neurturin, a relative of glial-cell-line-derived neurotrophic factor. Nature 1996;384:467-70.

124. Lin LF, Doherty DH, Lile JD, Bektesh S, Collins F. GDNF: a glial cell line-derived neurotrophic factor for midbrain dopaminergic neurons. Science 1993;260:1130-2.

125. Lonka-Nevalaita L, Lume M, Leppanen S, Jokitalo E, Peranen J, Saarma M. Characterization of the intracellular localization, processing, and secretion of two glial cell line-derived neurotrophic factor splice isoforms. J Neurosci. 2010;30:11403-13.

126. Eigenbrot C, Gerber N. X-ray structure of glial cell-derived neurotrophic factor at $1.9 \mathrm{~A}$ resolution and implications for receptor binding. Nat Struct Biol. 1997; 4:435-8.

127. Sandmark J, Dahl G, Oster $L, X u B$, Johansson $P$, Akerud $T$, et al. Structure and biophysical characterization of the human full-length neurturin-GFRa2 complex: a role for heparan sulfate in signaling. J Biol Chem. 2018;293:5492-508.

128. Lindholm P, Saarma M. Novel CDNF/MANF family of neurotrophic factors. Dev Neurobiol. 2010;70:360-71.

129. Runeberg-Roos P, Piccinini E, Penttinen AM, Matlik K, Heikkinen $H$, Kuure $S$, et al. Developing therapeutically more efficient neurturin variants for treatment of Parkinson's disease. Neurobiol Dis. 2016;96:335-45.

130. Bespalov MM, Sidorova YA, Tumova S, Ahonen-Bishopp A, Magalhaes AC, Kulesskiy $E$, et al. Heparan sulfate proteoglycan syndecan-3 is a novel receptor for GDNF, neurturin, and artemin. J Cell Biol. 2011;192:153-69.

131. Parkash V, Leppanen VM, Virtanen H, Jurvansuu JM, Bespalov MM, Sidorova YA, et al. The structure of the glial cell line-derived neurotrophic factor-coreceptor complex: insights into RET signaling and heparin binding. J Biol Chem. 2008;283:35164-72.

132. Hamilton JF, Morrison PF, Chen MY, Harvey-White J, Pernaute RS, Phillips $\mathrm{H}$, et al. Heparin coinfusion during convection-enhanced delivery (CED) increases the distribution of the glial-derived neurotrophic factor (GDNF) ligand family in rat striatum and enhances the pharmacological activity of neurturin. Exp Neurol. 2001;168:155-61.

133. Rosenblad C, Kirik D, Bjorklund A. Neurturin enhances the survival of intrastriatal fetal dopaminergic transplants. Neuroreport 1999;10:1783-7.

134. Piccinini E, Kalkkinen N, Saarma M, Runeberg-Roos P. Glial cell line-derived neurotrophic factor: characterization of mammalian posttranslational modifications. Ann Med. 2013;45:66-73.

135. Horger BA, Nishimura MC, Armanini MP, Wang LC, Poulsen KT, Rosenblad C et al. Neurturin exerts potent actions on survival and function of midbrain dopaminergic neurons. J Neurosci. 1998;18:4929-37.

136. Yu LY, Jokitalo $E$, Sun YF, Mehlen $P$, Lindholm D, Saarma M, et al. GDNF-deprived sympathetic neurons die via a novel nonmitochondrial pathway. J Cell Biol. 2003;163:987-97.

137. Gardner BM, Walter P. Unfolded proteins are Ire1-activating ligands that directly induce the unfolded protein response. Science 2011;333:1891-4.

138. Karagoz GE, Acosta-Alvear D, Nguyen HT, Lee CP, Chu F, Walter P. An unfolded protein-induced conformational switch activates mammalian IRE1. eLife. 2017;6: e30700.

139. Wang P, Li J, Tao J, Sha B. The luminal domain of the ER stress sensor protein PERK binds misfolded proteins and thereby triggers PERK oligomerization. J Biol Chem. 2018;293:4110-21.

140. Cullinan SB, Zhang D, Hannink M, Arvisais E, Kaufman RJ, Diehl JA. Nrf2 is a direct PERK substrate and effector of PERK-dependent cell survival. Mol Cell Biol. 2003:23:7198-209.
141. Cnop M, Toivonen S, Igoillo-Esteve $M$, Salpea $P$. Endoplasmic reticulum stress and elF2alpha phosphorylation: the Achilles heel of pancreatic beta cells. Mol Metab. 2017;6:1024-39.

142. Hetz C, Zhang K, Kaufman RJ. Mechanisms, regulation and functions of the unfolded protein response. Nat Rev Mol Cell Biol. 2020;21:421-38.

143. Karagoz GE, Acosta-Alvear D, Walter $P$. The unfolded protein response: detecting and responding to fluctuations in the protein-folding capacity of the endoplasmic reticulum. Cold Spring Harb Perspect Biol. 2019;11:a033886.

144. Preissler S, Ron D. Early events in the endoplasmic reticulum unfolded protein response. Cold Spring Harb Perspect Biol. 2019;11:a033894.

\section{ACKNOWLEDGEMENTS}

We thank Dr. Mikko Airavaara, Dr. Barry J. Hoffer, Dr. Vera Kovaleva, Dr. Maria Lindahl, and Dr. Raimo Tuominen for comments on the manuscript. Images in Figs. 2-4 were created with BioRender.com. Fig 2A was adapted from "UPR Signaling (ATF6, PERK, IRE1)", by BioRender.com (2021). Retrieved from https://app.biorender.com/ biorender-templates.

\section{AUTHOR CONTRIBUTIONS}

M.S. prepared an initial draft. M.S. and P.L. together wrote the paper, and P.L. prepared the figures. Both authors edited the manuscript and accepted the final version.

\section{FUNDING}

This work was supported by Jane and Aatos Erkko foundation and the Academy of Finland (grant number 1310891). Open Access funding provided by University of Helsinki including Helsinki University Central Hospital.

\section{COMPETING INTERESTS}

P.L. and M.S. are inventors in the CDNF- and MANF-related patents $(7,452,969$; $9,592,270)$ owned by Herantis Pharma Plc. M.S. is a minority shareholder in Herantis Pharma Plc. Intellectual property concerning CDNF fragments belongs to the University of Helsinki.

\section{ADDITIONAL INFORMATION}

Correspondence and requests for materials should be addressed to Mart Saarma.

Reprints and permission information is available at http://www.nature.com/ reprints

Publisher's note Springer Nature remains neutral with regard to jurisdictional claims in published maps and institutional affiliations.

Open Access This article is licensed under a Creative Commons Attribution 4.0 International License, which permits use, sharing, adaptation, distribution and reproduction in any medium or format, as long as you give appropriate credit to the original author(s) and the source, provide a link to the Creative Commons license, and indicate if changes were made. The images or other third party material in this article are included in the article's Creative Commons license, unless indicated otherwise in a credit line to the material. If material is not included in the article's Creative Commons license and your intended use is not permitted by statutory regulation or exceeds the permitted use, you will need to obtain permission directly from the copyright holder. To view a copy of this license, visit http://creativecommons. org/licenses/by/4.0/.

(c) The Author(s) 2021 